\title{
Enfrentando as Queixas: o Desenvolvimento da Atividade Voluntária para a Psicologia Histórico-Cultural
}

\author{
Ana Paula Alves Vieira ${ }^{1}$ \\ ${ }^{1}$ Universidade Estadual de Maringá, PR, Brasil.
}

\author{
Záira Fátima de Rezende Gonzalez Leal ${ }^{1}$ \\ ${ }^{1}$ Universidade Estadual de Maringá, PR, Brasil.
}

Resumo: Diante dos problemas no processo de escolarização relacionados à dificuldade na capacidade da criança em controlar seu comportamento (ter objetivos definidos em suas atividades e encontrar os meios para alcançá-los), se faz necessário compreender a gênese e o desenvolvimento dos processos psíquicos para fazer frente a essa situação. Este artigo deriva de uma dissertação que objetivou investigar como se desenvolve a atividade voluntária a partir da Psicologia Histórico-Cultural, bem como contextualizar as preocupações dos teóricos fundadores dessa abordagem relativas ao tema; situar o aumento de queixas de crianças com dificuldades relacionadas à atividade voluntária; entender esse processo na periodização do desenvolvimento. A pesquisa seguiu o método Materialista Histórico, buscando a origem, o desenvolvimento e as múltiplas determinações do objeto de pesquisa em questão. Foram realizados levantamentos bibliográficos no Portal de Periódicos Capes com palavras-chave que correspondiam à voluntariedade (Autocontrole/Autorregulação/ Atividade voluntária), "Psicologia escolar/educacional" e "Psicologia Histórico-Cultural" (Vygotski/Vygotsky/Vigotski) e nas obras de autores do enfoque histórico-cultural. Identificamos que o desenvolvimento da atividade voluntária se relaciona com a formação dos processos psicológicos superiores, a partir da atividade que medeia o indivíduo e a realidade em cada período do desenvolvimento, bem como pela formação da linguagem. $\mathrm{O}$ jogo de papéis consiste em uma atividade importante no desenvolvimento da voluntariedade, pois envolve a internalização de regras sociais e o desenvolvimento da hierarquia de motivos. A compreensão do desenvolvimento da voluntariedade contribui para a instrumentalização de profissionais acerca da não patologização do processo de ensino e aprendizagem e para a discussão e atuação crítica em Psicologia.

Palavras-chave: Psicologia Histórico-Cultural, Psicologia Escolar e Educacional, Atividade Voluntária, Desenvolvimento Humano. 


\title{
Facing the Complaints: the Development of Voluntary Activity for Historical-Cultural Psychology
}

\begin{abstract}
Faced with problems in the schooling process related to the difficulty in the child's ability to control his behavior (to have defined objectives in his activities and to find the means to reach them), it is necessary to understand the genesis and development of the psychic processes to face this situation. This article derives from a master's thesis that had as objective to investigate how the voluntary activity develops from the Historic-Cultural Psychology. This article also had as objectives: to contextualize the concerns of the founders of that approach related to the topic; to situate the increase of complaints of children with difficulties related to the volunteer activity; to understand this psychic process in the periodization of development. The research followed the Historical Materialist method, searching the origin, the development and the multiple determinations of the research object in question. Bibliographic surveys were carried out in Capes' database with keywords that corresponded to voluntary activity (Self-control/Self-regulation/voluntary activity), "School / educational psychology" and "Historical-Cultural Psychology" (Vygotsky/Vygotsky /Vygotsky) and in the works of the psychological focus in question. We identify that the development of voluntary activity relates to the formation of superior psychological processes, from the activity that mediates the individual and the reality in each period of development, as well as the language formation. The role play is an important activity in the development of voluntary activity, as it involves the internalization of social rules and the development of the hierarchy of motives. Understanding the development of voluntary activity contributes to the instrumentalization of professionals regarding the non-pathologization of teaching and learning and the discussion and critical action in psychology.
\end{abstract}

Keywords: Historic-Cultural Psychology, School and Educational Psychology, Voluntary Activity, Human Development. 


\title{
Enfrentando las Quejas: el Desarrollo de la Actividad Voluntaria para la Psicología Histórico-Cultural
}

\begin{abstract}
Resumen: Ante los problemas en el proceso de escolarización relacionados a la dificultad del niño en controlar su comportamiento (tener objetivos definidos en sus actividades y buscar los medios para logarlos), se hace necesario comprender la génesis y el desarrollo de los procesos psíquicos para que se haga frente a esa situación. Este artículo deriva de una tesis que tuvo como objetivos investigar cómo se desarrolla la actividad voluntaria desde la Psicología Histórico-Cultural, así como contextualizar las preocupaciones de los teóricos fundadores de ese abordaje relativas al tema; situar el aumento de quejas de niños con dificultades relacionadas a la actividad voluntaria; entender ese proceso en la periodización del desarrollo. La investigación siguió el método Materialista Histórico, buscando el origen, el desarrollo y las múltiples determinaciones del objeto de investigación en cuestión. Se realizaron encuestas bibliográficas en el Portal de Periódicos Capes con palabras-claves que correspondían a la actividad voluntaria (Autocontrol/Autorregulación/actividad voluntaria), "Psicología escolar/ educativa" y "Psicología Histórico-Cultural" (Vygotski/Vygotsky/Vigotski) y en las obras de autores del enfoque histórico-cultural. Identificamos que el desarrollo de la actividad voluntaria se relaciona con la formación de los procesos psicológicos superiores, a partir de la actividad que comprende al individuo y la realidad en cada periodo del desarrollo, así como por la formación del lenguaje. El juego de roles consiste en una actividad importante en el desarrollo de la actividad voluntaria, pues implica la internalización de reglas sociales y el desarrollo de la jerarquía de motivos. La comprensión del desarrollo de la voluntariedad contribuye a la instrumentalización de profesionales acerca de la no patologización del proceso de enseñanza y aprendizaje, y también para la discusión y actuación critica en psicología.
\end{abstract}

Palabras clave: Psicología Histórico-Cultural, Psicología Escolar y Educativa, Actividad Voluntaria, Desarrollo Humano.

\section{Introdução}

Hoje em dia os profissionais relacionados à educação, principalmente os psicólogos, têm se deparado com problemas de escolarização relacionados à dificuldade na capacidade da criança em controlar seu comportamento no sentido de ter objetivos definidos em suas atividades e encontrar os meios para alcançá-los, o que influencia diretamente na aprendizagem dos conteúdos escolares. O aumento de crianças diagnosticadas com Transtorno de Déficit de Atenção e Hiperatividade $(\mathrm{TDAH})$ tem crescido de forma alarmante (Anvisa, 2014), bem como de crianças que tomam o medicamento "do controle do comportamento" - que contém como princípio ativo o metilfenidato (Barros, 2011; Brasil, 2015; Campos, 2007; Stroufe, 2012).

Para lidar com essa situação, alguns profissionais atuam embasados por teorias que podem atribuir justificativas anistóricas ao desenvolvimento humano, desconsiderando ou diminuindo o papel da educação, bem como caracterizando esse inadequado controle como um transtorno passível de se tratar com medicamentos. A motivação de realizar essa pesquisa surgiu do contato com essa situação no trabalho como orientadora social em uma Organização Não Governamental (ONG). Se tratava em realizar oficina no período extraclasse com crianças de famílias que ganhavam bolsa-família. Devido à indisciplina, inquietação e agressividade apresentadas pelas crianças, era comum as atribuições de justificativas biológicas para esses problemas de controle do comportamento. Nesse sentido surgiu um incômodo relacionado às possibilidades da Psicologia em explicar esse desenvolvimento de uma forma que as ajudasse e não que patologizasse seu processo de ensino-aprendizagem com atribuição de diagnósticos de transtornos e distúrbios neuropsicológicos.

De acordo com Smirnova (2010), o problema do desenvolvimento da voluntariedade não aparece como central para a Psicologia, já que essa está interes- 
sada em encontrar os determinantes da conduta e da personalidade humana e não o processo de formação da autodeterminação. Nesse sentido, os autores Díaz, Neal e Amaya-Williams (1996) postulavam a existência de poucos estudos que se referem às origens e ao desenvolvimento da autorregulação e pesquisas mais recentes afirmam que os estudos que existem não consideram a dimensão social do processo, o que para o enfoque Histórico-Cultural é fundamental (Moreno, Ballesteros, Burke, \& Meraz, 2012). Também foi constatado que existem poucas produções brasileiras sobre esse fenômeno, principalmente relacionadas ao enfoque psicológico em questão (Vieira, 2016).

Nesse sentido, este artigo visa apresentar parte de uma pesquisa de mestrado (Vieira, 2017) que teve como objetivo geral compreender como se desenvolve, a partir da Psicologia Histórico-Cultural, o controle do comportamento, que denominamos de atividade voluntária devido às pesquisas realizadas que apontaram ser esse termo o mais condizente com a teoria (González, 2011; Salmina \& Filimonova, 2001; Smirnova, 2010). Dessa forma, entendemos que a atividade voluntária corresponde à atividade dirigida a um objetivo estabelecido.

Nos objetivos específicos apresentados neste artigo buscamos situar nossa preocupação atual relativa ao aumento de crianças com dificuldades relacionadas ao controle do comportamento; contextualizar as preocupações dos teóricos fundadores da Psicologia Histórico-Cultural relativas ao tema; buscar a definição de atividade voluntária para o enfoque psicológico em questão, compondo o estado da arte sobre os conceitos relacionados a esse processo e entender o processo psíquico na periodização do desenvolvimento. A expectativa é de que este trabalho possa contribuir para estudos e práticas que favoreçam o desenvolvimento infantil.

\section{Método}

A pesquisa se norteou a partir dos pressupostos filosóficos e metodológicos do materialismo histórico-dialético, já que esse é o método que sustenta a Psicologia histórico-cultural. Assim, buscamos ir além das aparências e buscar a essência dos fenômenos. De acordo com Vygotski (1996a, p. 383), "se a essência e a forma de manifestação das coisas coincidissem, diz Marx, toda ciência seria desnecessária [...]”.
De acordo com Tonet (2013) e Netto (2001), na análise científica deve-se buscar compreender as múltiplas determinações dos fenômenos, com a finalidade de apreendê-los na totalidade, para alcançar a sua essência. Nesse sentido, buscamos entender o desenvolvimento da atividade voluntária sob a perspectiva singular-universal, como afirma Elkonin (1987), compreendemos o desenvolvimento da criança na sociedade e não como independente dela. Ao investigar como se desenvolve o controle de comportamento, podemos criar situações que favoreçam a formação do psiquismo.

O problema da dificuldade de controle do comportamento pelas crianças nos é apresentado de uma forma aparente: o aumento crescente das crianças diagnosticadas com distúrbios ou transtornos psicológicos, que transfere os problemas sociais e educacionais em problemas médicos, fazendo aumentar a taxa de crianças medicalizadas e contribuindo para o aumento do fracasso escolar. Essa situação revela que tem prevalecido uma visão naturalista dos processos psicológicos como de ordem espontânea e orgânica unicamente. Essa concepção leva à culpabilização da criança pela sua dificuldade no processo de escolarização.

De acordo com Marx (1932/1978), a análise do fenômeno não deve ser descritiva, mas sim explicativa. Diante disso, buscamos compreender como se desenvolve a atividade voluntária a partir da Psicologia Histórico-Cultural (objetivo geral). Este estudo deriva de uma pesquisa de mestrado (Vieira, 2017), realizada no ano de 2015 à 2016, na qual primeiramente foi realizada uma consulta a um acervo de uma pesquisa anterior que foi apresentada como monografia de conclusão de curso da especialização em Teoria Histórico-Cultural na Universidade Estadual de Maringá (UEM) (Vieira, 2016). O acervo foi fruto de um levantamento bibliográfico no Portal de Periódicos da Coordenação de Aperfeiçoamento de Pessoal de Nível Superior com as palavras-chave "Autocontrole", "Autorregulação", "Psicologia escolar", "Psicologia educacional", "Psicologia Histórico-Cultural”, "Vygotski”, "Vygotsky”, "Vigotski". A busca foi realizada nos últimos dez anos. Esse acervo também foi composto por fontes primárias, relativas aos materiais de L. S. Vigotski1 ${ }^{1}$ (1896-1934), A. R. Luria (1902-1977), A. N. Leontiev (1903-1979).

Os resultados dessa pesquisa foram intrigantes e impulsionaram a pesquisa de mestrado, já que percebemos poucas produções e muitas divergências

\footnotetext{
${ }^{1}$ Prestes (2010) ao explicar os diferentes tipos de grafia para o "i” no alfabeto cirílico, conclui que na tradução direta do russo para o português, a forma de escrita Vigotski é a que mais se aproxima da escrita original. Por esse motivo, optamos por utilizar a grafia Vigotski no corpo deste trabalho, porém nas citações e nas referências será mantida a grafia de acordo com a obra consultada.
} 
nos artigos encontrados. Não foram localizadas, nos levantamentos realizados, pesquisas que, por meio da Psicologia Histórico-Cultural, analisassem o processo psicológico em questão, sendo que alguns autores apenas citaram os autores Luria e Vigotski para apresentar algum conceito específico, mas também apresentavam concepções construtivistas. Dessa forma, foi retomado esse acervo consultado a fim de buscar a gênese e o desenvolvimento do fenômeno.

Durante a pesquisa de mestrado foi realizado um período sanduíche em uma instituição mexicana - Maestría en Diagnóstico y Rehabilitación Neuropsicológica - pertencente à Benemérita Universidad Autónoma de Puebla (BUAP, Puebla, México), esse intercâmbio foi contemplado pelo programa de bolsas denominado Becas de Excelencia del Gobierno de México para Extranjeros, pertencente à Secretaría de Relaciones Exteriores de México. Devido ao contato com os pesquisadores dessa instituição, foram identificados novos materiais sobre o tema em questão e foi realizado um levantamento para identificação de outras referências e composição de um acervo a respeito, agora a partir dos descritores "atividade voluntária" e "Psicologia Histórico-Cultural”, a fim de compor o estado da arte desse tema. Esse levantamento foi realizado novamente no portal de periódicos da Coordenação de Aperfeiçoamento de Pessoal de Nível Superior (Capes) e nas fontes primárias/clássicas dos teóricos fundadores da Psicologia Histórico-Cultural, bem como de seus seguidores e intérpretes. Nesse momento foram lidos os títulos e resumos (quando se tratava de artigos) dos materiais para selecioná-los para leitura. Em relação às fontes primárias, foram consultados os materiais construídos por publicações dos autores já mencionados - Vigotski, Luria e Leontiev -, bem como Elkonin (1987; 1971/2012) e Gurevich (1969). Também foram analisados materiais dos continuadores e intérpretes da teoria em questão como Facci (2004), Mújina (1985), Salmina e Filinova (2001), Smirnova (2010), Solovieva e Quintanar (2001; 2012), Tuleski $(2008 ; 2011)$, dentre outros.

\section{Resultados}

A partir da pesquisa mencionada anteriormente, foi possível sistematizar os resultados da seguinte forma. Primeiramente analisamos que a situação aparente relacionada a problemas de controle de comportamento apresentados pelas crianças é de constante fracasso escolar, de aumento das quei- xas escolares e de aumento nos diagnósticos estigmatizantes. Posteriormente a isso, apresentamos os pressupostos da Psicologia Histórico-Cultural para explicar como essa abordagem entende o controle de comportamento e como se dá seu desenvolvimento na periodização da infância.

\section{A produção descontrolada das queixas escolares}

Os problemas que chegam ao psicólogo relacionados a dificuldades no processo de escolarização são denominados de queixas escolares. As queixas mais frequentes são os problemas de aprendizagem e de comportamento (Souza, 1997; 2000). Muitas dessas queixas são relacionadas às dificuldades no controle de comportamento apresentado pelas crianças, as quais chegam com suspeitas ou já diagnosticadas com algum transtorno ou déficit. O TDAH consiste em um deles, o qual é definido a partir dos sintomas de desatenção, hiperatividade e impulsividade no Diagnostic and Statistical Manual of Mental Disorders 5 [DSM 5] (APA, 2013).

Segundo o relatório da Agência Nacional de Vigilância Sanitária (Anvisa, 2014), o número de crianças e adolescentes com diagnóstico de TDAH tem crescido assustadoramente. De acordo com os Dados do Instituto Brasileiro de Defesa dos Usuários de Medicamentos, a venda do tipo de remédio usado no tratamento desse transtorno aumentou de 71 mil para 1.147.000 de 2000 a 2008 , aumento correspondente a $1.615 \%$ (Barros, 2011). Devido a essa grande porcentagem, a recomendação dada pelo Ministério da Saúde (Brasil, 2015) foi suspender o uso do medicamento.

São desconhecidos os riscos e as mudanças cognitivas que o medicamento para o tratamento do TDAH provocam, levando em conta que as crianças estão se desenvolvendo enquanto o remédio age, essa informação, que pode ser constatada na bula de um dos remédios - a Ritalina ${ }^{\circledR}$-, é preocupante. De acordo com a bula do medicamento: "O mecanismo pelo qual ele (metilfenidato) exerce seus efeitos psíquicos e comportamentais em crianças não está claramente estabelecido, nem há evidência conclusiva que demonstre como esses efeitos se relacionam com a condição do sistema nervoso central" (Ritalina - Bula completa, 2013, para. 34). Esse fenômeno de transformação de questões sociais e políticas em questões médicas é denominado "medicalização" (Moysés, \& Collares, 2011). De acordo com Collares e Moysés (1996), a ciência faz o uso de respostas biolo- 
gizantes a problemas de ordem social. Dessa forma, não é repensada a escola ou o sistema social, mas atribui-se doenças às crianças e as tratam com medicamentos para solucionar um problema que é de ordem social, patologizando a indisciplina escolar.

O aumento no consumo dos medicamentos reflete o aumento na quantidade de crianças diagnosticadas com transtornos de ordem neurológica. O uso de remédios se torna uma forma para que as crianças obtenham e/ou mantenham o controle de seus comportamentos. Muitos psicólogos reforçam essa situação ao avaliarem crianças com transtornos e não contribuírem para o desenvolvimento da atividade voluntária. Facci, Tessaro, Leal, Silva e Roma (2007) constataram que as queixas escolares são pouco analisadas pelos psicólogos brasileiros e, quando são investigadas, têm como base a visão psicométrica. As autoras afirmam que, ao fazer uso da abordagem psicométrica, é possível remeter-se à concepção inatista do desenvolvimento, o que significaria compreender a constituição do ser humano a partir de fatores maturacionais e hereditários.

O psicólogo não deve se pautar em uma visão inatista, de acordo com Souza (2000), ele deve, pelo contrário, desvelar os processos de escolarização junto com os envolvidos na dificuldade apresentada na queixa escolar, a fim de compreender o que a constitui. De acordo com Tanamachi e Meira (2003), o psicólogo deve realizar uma análise entre a produção da queixa escolar e os processos de subjetivação e objetivação dos indivíduos envolvidos - família, amigos, escola e sociedade -, pois a queixa se constitui em uma síntese de múltiplas determinações.

Analisando a produção desse fenômeno, devemos pensar que o modo de produção vigente impacta na formação de psiquismos, como apontou Marx (1932/1978), o modo de produzir a vida material implica na qualidade da produção da vida social, política e espiritual dos seres humanos. Com o resultado do avanço do capitalismo, temos "a diferenciação e fragmentação do tipo humano único em vários tipos de classes sociais separados - que se enfrentam -, bem como a corrupção e a distorção da personalidade humana e a sua sujeição a um desenvolvimento unilateral [...]" (Vygotsky, 1930/1998, p. 111).

O complexo processo de escolarização, portanto, é marcado pela sociedade de classes, pois implica em desigualdade no acesso aos bens produzidos pela humanidade de uma forma geral, inclusive ao conhecimento compartilhado na escola (Souza, 2002).
Assim se faz complexa também a tarefa de romper com as explicações tradicionais da constituição dos processos psicológicos que têm sido desenvolvidas pela Psicologia no decorrer da história (Facci, 2004).

De acordo com Eidt (2004), os diagnósticos para o TDAH realizados pelo psicólogo brasileiro são muitas vezes baseados no Diagnostic and Statistical Manual of Mental Disorders (DSM), manual criado pela American Psychiatric Association (APA). Em sua pesquisa, a autora constatou que em 33,63\% dos 352 prontuários observados referentes à crianças no setor de saúde pública na cidade de São Paulo, os psicólogos enquadravam as crianças nos sintomas descritos pelo DSM IV e davam o diagnóstico com apenas uma seção.

Nesse sentido, o entendimento do desenvolvimento humano a partir da abordagem psicométrica presente nesses testes e manuais remete à concepção inatista do desenvolvimento, caracterizada por compreender a constituição do ser humano a partir de fatores maturacionais e hereditários, solucionando-os por meio medicamentoso. De acordo com Machado (2000), o fato de acreditar na medição da inteligência e na capacidade individual desvinculada das relações sociais tornou-se natural, sendo essa a situação aparente do problema da dificuldade/falta de controle do comportamento.

Meira (2012, p. 139) afirma que a pergunta que tem sido feita a respeito da atenção é "o que a criança tem que não consegue prestar atenção?” e propõe a necessidade de inverter a pergunta para "o que na escola produz a falta de atenção e concentração?". Nesse mesmo sentido, propomos, neste trabalho, que a pergunta relacionada ao desenvolvimento do controle do comportamento seja também colocada no sentido cultural e histórico, buscando entender o que na família e na sociedade produz crianças "descontroladas" e não corroborando com explicações deterministas que resultam no uso de medicamentos como solução para controlar e regular estas crianças. Para realizar esse enfrentamento é necessário um enfoque que tenha uma visão além do desenvolvimento biológico, como a Psicologia Histórico-Cultural, por exemplo.

\section{Pressupostos da Psicologia Histórico-Cultural e a conceituação da atividade voluntária}

O controle de comportamento, dentre várias temáticas, já era um problema apontado pelos psicólogos histórico-culturais no contexto pós-revolucionário em que viviam. O grupo de estudos que buscava formar 
uma nova Psicologia era composto por L. S. Vigotski, A. R. Luria e A. Leontiev - "gran tercio" ou "troika" considerados os fundadores da Psicologia Histórico-Cultural (Luria, 1979/2015a) -, juntamente com uma equipe de pesquisadores. Esse grupo de estudos se constituiu na década de 1920, após a Revolução Soviética de 1917.

Essa nova Psicologia partia dos princípios do materialismo histórico, contrariando as visões idealistas e materialistas da época. Para esse enfoque, as peculiaridades do comportamento humano são investigadas "na forma histórico-social de atividade, que está relacionada com o trabalho social, com o emprego de instrumentos de trabalho e com o surgimento da linguagem" (Luria, 1991, pp. 74-75). Segundo Tuleski (2008), tais teóricos estavam comprometidos com a construção do novo projeto de sociedade e, para isso, propuseram uma nova Psicologia que pudesse compreender a formação humana como passível de transformação, assim como já acontecia com as forças produtivas na União Soviética.

A União Soviética era praticamente toda agrária e foram muitas as dificuldades socioeconômicas após a revolução, de acordo com Tuleski (2008). Considerava-se que a saída para as dificuldades do setor agrícola no período pós-revolucionário era acelerar a industrialização e, para que isso se concretizasse, houve um reforço disciplinar no interior das fábricas. Contrários a essa coerção externa e ao autoritarismo que estava acontecendo devido à acelerada industrialização, Vygotsky e Luria (1930/1996) demonstraram cientificamente o processo de formação cultural do ser humano. Os autores defendiam que é por meio da apropriação dos signos e instrumentos culturais que as funções psicológicas superiores se desenvolvem e são capazes de promover a autorregulação do comportamento. Nessa perspectiva, os comportamentos impulsivos, imediatistas/instintivos e sem reflexão poderiam ser abandonados, já que, por meio da educação para o trabalho com percepção da totalidade das relações e do coletivo, se desenvolveria um comportamento racional compatível com o sistema comunista, sem necessidade de coerção externa (Tuleski, 2008).

Dentro desse contexto mencionado, identificamos nas obras selecionadas que Vigotski escreve sobre a voluntariedade, o autocontrole, o autodomínio e a autorregulação, mas não aponta uma distinção entre esses processos (Vieira, 2016). Assim, no próximo item expomos o que os autores postulam sobre o desenvolvimento do controle de comportamento.
A autodominação do comportamento e o conflito de motivos

De acordo com Vygotski (1960/2012), a chave para a dominação da conduta consiste em que as formas de conduta que os adultos aplicam em relação à criança ao longo do desenvolvimento infantil passam depois a serem utilizadas por ela mesma. Vigotski (1934/2009) denomina de zona de desenvolvimento próximo a zona de possibilidades das crianças, em que estão os processos psíquicos que estão se consolidando, os quais estão refletidos nas tarefas que as crianças conseguem realizar com auxílio do adulto (ações compartilhadas) e que depois passam a compor sua zona de desenvolvimento real, ou seja, passam a serem apropriadas pelas crianças. Dessa forma, a lei genética geral do desenvolvimento cultural para Vigotski é que toda função aparece em dois planos: primeiro no plano social (interpsíquico), depois no psicológico (intrapsíquico).

Nesse sentido, Vygotski (1960/2012, p. 84) questiona "O que devemos entender como domínio da própria conduta?”. Para o autor, assim como o domínio da natureza não pressupõe a abolição das leis básicas da natureza, o domínio do próprio comportamento também não, mas sim uma subordinação dessas leis. Pensando na lei de estímulo-resposta, a dominação do comportamento corresponde a uma dominação dos estímulos. Dessa forma, o ser humano supera o comportamento de estímulo-resposta dos animais, pois atribui significado histórico para o estímulo. De acordo com Vygotski (1960/2012), a significação é o princípio de criação e uso de signos, em que o homem, a partir de uma necessidade externa, forma conexões no cérebro e se autogoverna. De acordo com o autor, a equação da conduta primitiva de estímulo-resposta se transforma em uma equação com dois polos: estímulo-signo e estímulo-objeto. Essa nova estrutura representa o processo de dominação do comportamento.

O papel dos estímulos-signos, ou seja, aqueles estímulos criados pelo homem - artificiais -, é de dominar sua própria conduta. "O homem, sem dúvida, submete o poder das coisas sobre sua conduta, o põe a serviço de seus objetivos e orienta a seu modo. Com sua atividade externa modifica o meio circundante e influi, assim, sobre seu próprio comportamento, o subordina a seu poder" (Vygotski, 1960/2012, p. 292). $\mathrm{O}$ autor cita um exemplo sobre a autodominação por meio dos estímulos: em uma situação na qual uma pessoa precisa esperar muito tempo em uma habita- 
ção vazia e não sabe se continua esperando ou se vai embora (conflito de motivos), o comportamento de olhar o relógio intensifica um dos motivos, por exemplo, se for tarde ele decidirá ir embora. O relógio se converte em estímulo e adquire o significado de um motivo auxiliar, podendo o sujeito delimitar um horário para se levantar e sair. Assim, o homem interfere em seu comportamento por meio de um estímulo externo, introduzindo um motivo auxiliar.

De acordo com Smirnova (2010), "Leontiev considerava o desenvolvimento da conduta voluntária em relação ao desenvolvimento e à diferenciação da esfera motivacional" (p.49), sendo que o que caracteriza a atividade voluntária é a presença de motivo e do objetivo, que são as características principais desse processo. L. I. Bozhovich (citado por Smirnova, 2010), relacionava a formação de motivos com o desenvolvimento da vontade e da voluntariedade. Sobre os dois termos - vontade e voluntariedade -, existem divergências e confusões entre autores. A análise realizada por Smirnova (2010) resulta em que o problema do desenvolvimento do comportamento voluntário foi incluído em dois níveis: da formação das necessidades e motivos (vontade) e do desenvolvimento dos processos cognitivos (voluntariedade).

De acordo com Leontiev (1975/1984) as condições externas que o homem se relaciona têm, antes de tudo, caráter social, ou seja, advém de relações humanas, portanto carregam engendrados os motivos e objetivos da atividade, bem como os meios para realizá-la. Dessa forma, Leontiev e seus colaboradores apontam a atividade como o objeto de estudo da Psicologia. Atividade, nas palavras de Leontiev (1972/2013), consiste em "uma unidade não aditiva da vida material [...] no plano psicológico, é uma unidade de vida, mediada pela reflexão mental, por uma imagem, cuja função real é orientar o sujeito no mundo objetivo" (n.p.). Importante destacar que o indivíduo não só acomoda sua atividade na relação com a sociedade, mas que as condições sociais levam a formação dos motivos e fins da atividade, bem como os meios para realizá-la, nas palavras do autor: "a sociedade produz a atividade dos indivíduos que a formam” (Leontiev, 1975/1984, p. 68).

Os fins da atividade estão relacionados com a atividade voluntária; de acordo com Gurevich (1969) a atividade voluntária consiste no reconhecimento consciente dos fins e dos meios para alcançá-los. Acrescentando ao que postulou Leontiev, Gurevich (1969) afirma que a origem dos atos voluntários está relacionada com o trabalho social e exemplifica com o comportamento do homem primitivo, em que a satisfação da necessidade de comer não era imediata, em que o homem criava instrumentos (caça e pesca) que eram coletivos (trabalho social), dominando a natureza e dominando a si mesmo, desenvolvendo o ato voluntário (reconhecimento consciente do fim e dos meios para alcançá-lo).

O trabalho continua sendo a base do desenvolvimento dos atos, assim "o homem atua não somente para satisfazer suas necessidades, mas também para satisfazer as necessidades da sociedade" (Gurevich, 1969, p. 388). Dessa forma, os fins propostos pelo indivíduo são derivados das exigências da sociedade em que vive, pois, para alcançá-los, deve renunciar a suas necessidades imediatas e reprimir seus desejos, caso não estejam em consonância com os fins propostos. Para resolver essa situação, o indivíduo deve compreender conscientemente a significação social ${ }^{2}$ desses fins propostos. Assim, como na sociedade capitalista existe uma divisão entre o indivíduo e a sociedade, os quais são vistos a partir de uma relação de oposição, essa compreensão da significação social para a formação do significado pessoal se realiza de forma que promove um desenvolvimento unilateral e não integral.

Vygotski (1960/2012) destaca duas mudanças - uma orgânica e outra cultural - como muito significantes para o domínio do comportamento nos primeiros anos de vida da criança. A mudança orgânica é referente ao desenvolvimento físico-motor, pois esse fato muda a sua acomodação no espaço, ampliando seu poder sobre as coisas. Já a mudança cultural se dá quando a criança domina a linguagem. Dessa forma, as primeiras palavras acompanham o gesto indicador e se forma uma conexão com o entorno e de influência sobre as outras pessoas. A linguagem, portanto, se converte no meio de influência sobre o exterior.

Portanto, a palavra mediatiza a interação com os adultos e também mediatiza a atividade cognitiva. $\mathrm{Ou}$ seja, a linguagem não é usada somente para a comunicação, mas também para a orientação, regulação e

\footnotetext{
${ }^{2}$ Para maior aprofundamento sobre a oposição entre significado e significado pessoal causada pelo modo de produção capitalista ver texto "Atividade e Consciência" de Leontiev (1972/2013), o qual foi publicado em russo em 1972 na revista Voprosy filosofii, n. 12, 129-140 e em inglês no livro "Filosofia na URSS: Problemas do Materialismo-Dialético", de 1977. Em português se encontra disponível no site: https://www.marxists.org/portugues/leontiev/1972/mes/atividade.htm.
} 
planejamento da atividade. A princípio a linguagem da criança é usada para rotular o ambiente e descrever suas atividades, mas depois sofre modificações e não só acompanha as atividades da criança como também as precede (Vygotski, 1960/2012). Portanto, a linguagem tem um papel importante na regulação da conduta.

\section{A função reguladora da linguagem e os mecanismos cerebrais da atividade}

Luria (1962/2015b) postula que no ser humano, a linguagem "[...] formula o objetivo da ação, o correlaciona com o motivo e traça o esquema fundamental daquele problema que o homem levanta" (p. 298). De acordo com o autor, primeiro a ação da criança se determina pela ordem do adulto (ação repartida entre pessoas), depois se converte em uma ação regulada pela própria criança, primeiro por sua atividade perceptiva, depois pela sua linguagem externa desenvolvida e, posteriormente, por ideias e esquemas formulados pela participação da linguagem interna. Essa linguagem desenvolvida por último participa na transformação da informação recebida em ação com objetivo. Nesse sentido, Luria (1982/2001), assim como Vigotski, afirma que a linguagem externa é interiorizada, constituindo a linguagem interna, que é o principal instrumento regulador do comportamento humano.

O autor afirma que o componente verbal é a base das formas mais complexas de regulação do ato motor voluntário complexo (em ações voluntárias mais simples o componente verbal é menos necessário, já que essas ações se limitam na formulação do propósito e na realização de estereótipos motores). Apesar da criação de um esquema geral de ação, a influência reguladora da linguagem externa ou interna está também no transcurso da realização da ação, ou seja, no processo de vigilância e de controle da efetividade da ação. Dessa forma, a linguagem "ajuda a comparar a ação realizada com o propósito inicial, formulando sinais de concordância ou discordância, corrigindo os erros cometidos, interrompendo a atividade se o objetivo foi cumprido, ou reformulando-a se tal objetivo não foi conquistado" (Luria, 1962/2015, p. 299).

Os experimentos realizados por Luria (1976/1990) demonstram a função reguladora da linguagem, pois o autor observa que crianças pré-escolares, as quais não têm a linguagem como reguladora do comportamento, reagiam de maneira impulsiva, ou seja, tinham uma imediata transferência para a esfera motora. Nos estudos de Luria sobre neuropsicologia, o autor confirma que a atividade voluntária possui gênese histórica e cultural, ou seja, não é uma simples função natural do sistema nervoso central (Tuleski, 2011).

Sobre a conceituação da atividade voluntária, de acordo com Solovieva e Quintanar (2001), esse seria um termo próprio da Escola Psicológica Soviética (referindo-se à Escola Histórico-Cultural). Segundo os autores, o caráter voluntário não está relacionado com uma função, mas sim com a formação adequada de todos os processos psicológicos superiores, ou seja, se relaciona com a organização da atenção, da memória, da linguagem, do pensamento e da esfera afetivo-emocional. Outra observação decorrente da pesquisa foi como se desenvolve na criança esse processo, como está apresentado a seguir.

\section{O desenvolvimento da atividade voluntária na periodização da infância}

De acordo com Smirnova (2010), existem diferentes pontos de vista relacionados ao momento que surge a vontade ou a voluntariedade do comportamento. Segundo estudo realizado pela autora, alguns relacionam o aparecimento da atividade voluntária com os primeiros movimentos do bebê que são orientados a um fim, como os autores Zaporozhets e Lisina. Outros consideram quando as ações da criança começam a ser mediadas pela linguagem do adulto na primeira infância, como sugere também Lisina e outros. Há também autores que relacionam a formação do comportamento voluntário com a idade pré-escolar a partir do surgimento da hierarquia de motivos, como Leontiev, e a possibilidade de atuar segundo um modelo, como Elkonin. Por fim, autores que consideram o início da regulação voluntária na idade escolar ou na adolescência, como Bozhovich, Slavina e Endovitskaya. Devido a esse levantamento bibliográfico realizado por Smirnova (2010), detalharemos mais o período da idade pré-escolar como importante no desenvolvimento desse processo.

A idade pré-escolar corresponde aproximadamente a idade de três a sete anos (Elkonin, 1987; 1971/2012; Mújina, 1985; Vygotski, 1996b). De acordo com Leontiev (1987) e com a Psicologia infantil soviética em geral, a idade pré-escolar consiste em uma etapa importante na formação da esfera volitiva-emocional, dos interesses e dos motivos da conduta (Mújina, 1985). De acordo com Leontiev (1987, 1948/2010), a criança pré-escolar consegue separar 
os motivos mais importantes e subordinar os outros. Até dois anos ou dois anos e meio aproximadamente, a criança além de se mover livremente e manipular os objetos acessíveis e conhecidos, fala e se guia conscientemente pelo que vê e escuta dos adultos, demonstrando que ela já manifesta certa iniciativa e autonomia. Porém a peculiaridade que diferencia o comportamento da criança nessa idade de outra com uma idade maior é que "a criança, que ainda não tenha alcançado a idade pré-escolar, se encontra em poder das impressões externas. Por isso é muito fácil atraí-lo para algo, mas também é fácil distraí-lo" (p. 59). Por exemplo, a criança que perde um brinquedo se consola se o adulto lhe dá outro ou que a ocupe com alguma coisa.

Dessa forma, Gurévich (1938 citado por Leontiev, 1987) apresentou em sua tese intitulada Sobre la teoría de la acción voluntária, um estudo sobre quando e em que momento aparece a subordinação de motivos. Em um dos experimentos que realizou, era criada a seguinte situação com as crianças: quando a criança que estava montando mosaicos se entediava, lhe era oferecido um brinquedo muito interessante, mas a criança só podia brincar depois que guardasse as peças do mosaico nas caixas separadas por cores. Dessa forma a criança deveria realizar uma ação que não queria para brincar com o brinquedo interessante.

$\mathrm{O}$ autor verificou que a subordinação dos motivos se dá a partir dos três anos de idade e afirma que o cumprimento de uma ação em prol de outra se forma a partir da comunicação com o educador (situação social) e somente depois se torna possível de forma autônoma. Esse comportamento só é possível porque se dá sobre as bases das relações humanas mais complexas que a criança entra. A inclusão do pré-escolar nessas relações se dá de diferentes formas: uma delas é por meio do jogo de papéis (Leontiev, 1987; 1948/2010).

Em situação da brincadeira de jogo de papéis a criança pré-escolar menor consegue controlar sua conduta de uma forma que ainda não consegue em outras situações. Um estudo apresentado por Z. V. Manuilenko (citado por Leontiev, 1948/2010), denominado $O$ desenvolvimento da conduta voluntária nas crianças de idade pré-escolar, consistia em dar de forma direta a tarefa de conservar a posição de guarda. Nessa pesquisa, observou-se que as crianças pré-escolares menores não conseguiam cumprir a tarefa dada, mesmo quando se propunham com animação a fazer, elas se distraiam facilmente com alguma outra coisa. A tarefa dada dessa forma tinha um motivo determinado e sentido, que seria cumprir as exigências do adulto.

Leontiev (1948/2010) conclui que "isso se explica porque nas condições de brincadeira a relação entre o objetivo (conservar a pose) e o motivo, ao qual esse se submete, se encontra nas relações que, psicologicamente, são mais simples para as crianças" (p. 24). Na brincadeira se torna mais simples porque a criança, ao assumir o papel de guarda, assume também as relações comportamentais do papel, podendo cumprir a ação que será possível posteriormente na forma autônoma. De acordo com Mújina (1985), as crianças colocam regras nos papéis que incorporam, avaliando o desempenho delas e dos amigos, o qual pode ser visto nas expressões de crianças quando brincam: "tem que ser assim... não é assim... assim está bom... assim está ruim" (p. 62). Essa situação mostra que o conteúdo do jogo passa a ser subordinado pelas regras, colocando a disciplina e o autodomínio em primeiro plano.

De acordo com Elkonin (1987), a criança modela as relações entre as pessoas a partir do jogo, influenciando a formação de sua personalidade e o desenvolvimento do psiquismo da criança, por isso a brincadeira se constitui em uma atividade proeminente ${ }^{3} \mathrm{da}$ etapa pré-escolar.

Sobre o conceito de atividade proeminente, esta não consiste naquela que ocorre com mais frequência em determinada etapa do desenvolvimento, mas sim àquela que contém as seguintes características básicas: 1. Corresponde à atividade em que, em seu interior, surgem e se diferenciam outros tipos de atividades; 2. Consiste naquela em que reorganizam os processos psíquicos; É a atividade que produz as principais mudanças psicológicas na personalidade infantil (Leontiev, 2014). Outra mudança que ocorre a partir da atividade dominante apresentada por Leontiev (2014) se refere às funções psicofisiológicas, as quais se desenvolvem e se reestruturam dentro dessa atividade.

\footnotetext{
${ }^{3}$ Os termos utilizados nos textos consultados referentes a esse processo foram "atividade guia", "atividade principal” e "atividade dominante", porém, Bissoto (2012), nas notas de tradução do texto de Elkonin intitulado "Enfrentando o problema dos estágios no desenvolvimento mental das crianças" afirma, de acordo com Nikolai Veresov (1971 citado por Bissoto, 2012) que esse termo - "atividade dominante" - não reflete o papel da atividade no desenvolvimento mental, o termo mais próximo do russo - "veduschaya deyatelnost" - seria "atividade proeminente".
} 
Como percebemos, várias mudanças ocorrem no desenvolvimento psíquico da criança pré-escolar, sendo que a brincadeira possui um papel importante nesses processos. Dessa forma, compreendemos que a partir das atividades da criança, particularmente da atividade proeminente, se constroem as neoformações em cada período (dependendo da oferta dos produtos culturais e do processo de apropriação). De acordo com García, Solovieva e Quintanar (2013), González (2011) e Salmina (2010) as neoformações do período pré-escolar são: o domínio dos meios, a consideração da posição de outra pessoa e a atividade voluntária (possibilidade de regular e organizar sua própria conduta). Vygotski (1996b) já sinalizava a importância das novas formações e que essas se davam no período de crise.

Além do jogo de papéis, Mújina (1985) destaca outras brincadeiras no desenvolvimento de qualidades volitivas, como o desenho, a brincadeira de construção, dentre outras brincadeiras em que se tem um fim produtivo, ou seja, que objetive criar um produto. Mújina (1985) também destaca as tarefas laborais no desenvolvimento das qualidades volitivas. O motivo social de trabalho de fazer algo útil para outras pessoas faz com que se desenvolva a vontade do pré-escolar, com outras palavras, diferentes motivos organizam a atividade da criança de distintas formas. Um exemplo é quando se pede às crianças que façam bandeirinhas para que elas mesmas brinquem (motivo um) ou para presentear às crianças menores (motivo dois). As crianças cumpriram a tarefa em um tempo maior e a finalizaram no segundo caso. Segundo Mújina (1985), "quanto maior é para a criança a necessidade e a utilidade social do que faz, mais firmemente se orienta até o fim de seu trabalho" (p. 76). Nesse sentido, a autora afirma que o sentimento de dever se origina a partir da valorização que os adultos dão para os atos realizados pelas crianças, que embasa o surgimento da autovalorização, sendo uma das novas formações básicas da idade pré-escolar.

A atividade pedagógica é importante nesse sentido, porque, a atividade voluntária e as demais neoformações dessa etapa pré-escolar, de acordo com Elkonin (1980), preparam a criança para a sua atividade futura - estudo -, preparando-a, portanto para a escola. Por isso, encontramos na literatura (Leontiev, 1987; 1948/2010; Mújina, 1985; Salmina, 2010; Salmina, \& Filinova, 2001; Smirnova, 2010, Solovieva, \& Quintanar, 2012) um destaque à importância dessa etapa do desenvolvimento para a preparação para a escola com a formulação de avaliações que analisam essa preparação e de práticas que promovam esse desenvolvimento.

\section{Considerações finais}

As queixas escolares relacionadas ao problema da atividade voluntária expõem as condições de desenvolvimento em que vivemos. Entendendo a importância da significação social no desenvolvimento de motivos e que o desenvolvimento humano advém da apropriação do que a humanidade produziu, conhecimento esse que é passado de geração em geração pela educação, percebemos os prejuízos no desenvolvimento desse processo na forma como a sociedade está organizada.

Vivemos uma situação de aumento de crianças "descontroladas", pelo constante fracasso escolar com o abandono da escola e diversos problemas decorrentes da falta de aprendizagem, pelo crescimento em ritmos assustadores nas quantidades de diagnósticos possibilitados pelos manuais como o DSM, bem como pelo aumento no número de crianças diagnosticadas com o Transtorno de Déficit de Atenção e Hiperatividade e o decorrente uso de medicamentos para o seu tratamento.

Entendemos que a produção do fracasso escolar, das queixas e do aumento de diagnósticos é embasada por concepções teóricas que não compreendem o caráter histórico e cultural do desenvolvimento infantil. Assim, o problema do controle de comportamento é resolvido de forma médica, situação que se torna natural para as pessoas em geral. Reconhecemos os avanços nas discussões sobre a medicalização realizados tanto pela Psicologia Escolar quanto pela Psicologia Social, mas essa situação aparente ainda necessita análise, para que se entenda a real natureza do fenômeno e se apontem soluções que contribuam para o desenvolvimento humano.

Dessa forma, analisamos neste trabalho que o desenvolvimento da atividade voluntária, a qual se relaciona com a formação adequada de todos os processos psicológicos superiores - atenção, da memória, da linguagem, do pensamento e da esfera afetivo-emocional, se dá a partir da relação estabelecida entre o indivíduo e a realidade, pelas atividades realizadas em cada período do desenvolvimento. A atividade guia que mais se relaciona ao desenvolvimento da atividade voluntária consiste na brincadeira de jogo de papéis no período pré-escolar, pois a criança, ao brincar, segue regras sociais incorporadas no papel desem- 
penhado, o que impulsiona a internalização dessas regras e o desenvolvimento do controle do comportamento. A partir dessa brincadeira desenvolve-se, ainda, a hierarquia de motivos, em que a criança deixa de fazer alguma coisa atrativa para realizar outra ação menos interessante, seguindo as regras de seu papel. Ressaltamos aqui que a brincadeira importante para o desenvolvimento da criança não é qualquer uma, mas sim aquela organizada e pensada pelo adulto. Como foi exposto, a partir da pesquisa citada de Smirnova (2010), outras atividades são importantes para o desenvolvimento da atividade voluntária, mas existe um determinado consenso para os teóricos da Psicologia histórico-cultural que a brincadeira de jogo de papéis contribui muito para essa formação.

A teoria também possibilita-nos questionar o uso de medicamentos como alternativa à regulação externa. A partir da compreensão de que o controle voluntário se desenvolve em um processo no qual o meio externo tem influência direta e onde a linguagem tem um papel fundamental (o desenvolvimento das funções psíquicas se dá do meio externo ao interno), podemos pensar que se a criança faz uso do medicamento para se regular, seu desenvolvimento pode ser comprometido. Assim, no lugar da criança desenvolver essa autorregulação, ela pode ficar dependente do remédio para tal finalidade.

Nesse sentido, é importante a realização de pesquisas em Psicologia que busquem entender o desenvolvimento cultural do homem para que haja uma ampliação no conhecimento sobre o tema. Ao perceber a relação estreita entre aprendizagem e desenvolvimento, que os processos psíquicos são desenvolvidos da realidade externa para a interna, ou seja, do sentido interpsíquico para intrapsíquico, os adultos se percebem, nesse processo, como responsáveis pelo desenvolvimento da criança, bem como podem entender que uma educação pautada na coletividade pode contribuir para o desenvolvimento da atividade voluntária. A partir dessa concepção, podem pensar na criação de situações que favoreçam esse desenvol- vimento. Como foi apontado no texto, estudos mostram que uma das atividades direcionadas pelo adulto que tem importância fundamental para o desenvolvimento da voluntariedade consiste no jogo de papéis para o período pré-escolar. É função dos profissionais da educação terem o conhecimento da importância do direcionamento pedagógico na brincadeira e em todas as atividades.

Dessa forma, acreditamos que estudos como o apresentado neste trabalho são necessários para a formação do psicólogo que pode atuar melhor a partir de uma base teórica sólida que caminha na contramão do discurso hegemônico que favorece a categorização de sujeitos. Esperamos que esse trabalho possa auxiliar futuras pesquisas sobre o tema. Também esperamos contribuir para a instrumentalização de psicólogos e outros profissionais relacionados à educação.

A dificuldade da pesquisa consistiu no curto tempo para sua realização. A conceituação da atividade voluntária e de seu desenvolvimento demanda mais estudos acerca do fenômeno, que o tempo de pesquisa não permitiu. Alguns conceitos merecem mais aprofundamento como o de sentido e significado, apresentados especialmente por Leontiev e Vigotski, e da função reguladora da linguagem, especialmente apontada por Luria, bem como um aprofundamento no conceito e no estudo da vontade também abordada pelos teóricos. Portanto, consideramos necessárias mais pesquisas sobre os processos psicológicos baseados na Psicologia Histórico-Cultural, a fim de que a melhor compreensão da gênese social dos fenômenos leve a práticas e intervenções mais eficazes que promovam o desenvolvimento.

Também consideramos necessário, a partir do contato com a instituição estrangeira, que sigamos desenvolvendo a Psicologia Histórico-Cultural no Brasil, com mais trabalhos a respeito da avaliação psicológica baseada nesse enfoque psicológico, bem como o desenvolvimento de propostas metodológicas para a atuação prática do profissional, que necessita de ferramentas para compreender e atuar na realidade.

\section{Referências}

Agência Nacional de Vigilância Sanitária - Anvisa. (2014). Metilfenidato no tratamento de crianças com transtorno de déficit de atenção e hiperatividade. Boletim Brasileiro de Avaliação de Tecnologias em Saúde, 8(23). Recuperado de http://portal.anvisa.gov.br.

American Psychiatric Association - APA. (2013). Diagnostic and statistical manual of mental disorders DSM 5. Washington, DC: o autor. 
Barros, A. C. (2011, 28 de junho). Psicóloga: Ao invés de reverem a educação, usam Ritalina. Jornal do Brasil. Recuperado de http://www.jb.com.br/pais/noticias/2011/06/28/psicologa-ao-inves-de-reverem-a-educacao-usam-ritalina/

Brasil. (2015, 1 de outubro). Ministério da Saúde. Recomendações do Ministério da Saúde para adoção de práticas não medicalizantes e para publicação de protocolos municipais e estaduais de dispensação de metilfenidato para prevenir a excessiva medicalização de crianças e adolescentes. Recuperado de http://portalsaude.saude. gov.br/images/pdf/2015/outubro/01/Recomenda----es-para-Prevenir-excessiva-Medicaliza-----o-de-Crian--a-e-Adolescentes.pdf

Bissoto, M. L. (2012). Notas de tradução. In D. B. Elkonin, Enfrentando o problema dos estágios no desenvolvimento mental das crianças. Educar em Revista, (43), 149-172.

Campos, A. (2007). Geração Ritalina. Portugal: Educare.

Collares, C.A.L., \& Moysés, M.A.A. (1996). Preconceitos no cotidiano escolar: Ensino e medicalização. São Paulo, SP: Cortez.

Díaz, R. M., Neal, C. J., \& Amaya-Williams, M. (1996). As origens sociais da auto-regulação. In L. C. Moll (Org.), Vigotsky e a educação: implicações pedagógicas da psicologia sócio histórica (pp. 123-149). Porto Alegre, RS: Artmed.

Eidt, N.M. (2004). Transtorno de déficit de atenção e hiperatividade: diagnóstico ou rotulação (dissertação). Pontifícia Universidade Católica de Campinas, Campinas, SP, Brasil.

Elkonin, D. B. (1980). Psicología del juego. Madrid:Visor.

Elkonin, D. B. (1987). Sobre el problema de la periodización del desarrollo psíquico en la infancia. In D. Davidov, \& Y. Shuare (Orgs.), La psicología evolutiva y pedagógica en la URSS: Antología (pp. 104-124). Moscou: Ed. Progreso.

Elkonin, D. B. (2012). Enfrentando o problema dos estágios no desenvolvimento mental das crianças (M. L. Bissoto, Trad.). Educar em Revista, (43), 149-172. https://doi.org/10.1590/S0104-40602012000100011. (Original publicado em 1971).

Facci, M. G. D. (2004). A periodização do desenvolvimento psicológico individual na perspectiva de Leontiev, Elkonin e Vigostski. Caderno Cedes, 24(62), 64-81. https://doi.org/ 10.1590/S0101-32622004000100005

Facci, M. G. D., Tessaro, N. S., Leal, Z. F. R. G., Silva, V. G., \& Roma, C. G. (2007). Psicologia histórico-cultural e avaliação psicológica: O processo ensino aprendizagem em questão. Revista Semestral da Associação Brasileira de Psicologia Escolar e Educacional (ABRAPEE), 11(2), 323-338.

García, M. A., Solovieva, Y., \& Quintanar, L. (2013). El desarrollo de neoformaciones a través del juego y del cuento en niños preescolares. Cultura y Educación, 25(2), 183-198.

González, C. T. (2011). Efectos de la aplicación de un programa de juego de roles en el desarrollo de la actividad voluntaria en preescolares mayores (dissertação). Benemérita Universidad Autónoma de Puebla, Puebla, México.

Gurevich, K. M. (1969). Los actos voluntarios. In A. A. Smirnov, A. N. Leontiev, S. L. Rubinstein, \& B. M. Tieplov (Orgs.), Psicologia (pp. 385-403). México: Grijalbo.

Leontiev, A. N. (1984). Actividad, conciencia y personalidad. México, DC: Editorial Catargo de México. (Trabalho original publicado em 1975).

Leontiev, A. N. (1987). El desarollo psíquico del niño en la edad preescolar. In V. Davídov, \& M. Shuare (Orgs.), La psicologia evolutiva y pedagogia em la URSS: antologia (pp. 57-70). Moscú: Progreso.

Leontiev, A. N. (2010). El desarrollo psicológico en la edad preescolar. In Y. Solovieva, \& L. Quintanar (Orgs.), Antología del desarrollo psicológico del niño en edad preescolar (pp.17-26). México, DF: Trillas. (Trabalho original publicado em 1948).

Leontiev, A. N. (2013). Atividade e consciência (M. J. S. Silva, Trad.). Recuperado de https://www.marxists.org/portugues/leontiev/1972/mes/atividade.htm

Leontiev, A. N. (2014). Uma contribuição à teoria do desenvolvimento da psique infantil. In L. S. Vigotskii, A. R. Luria, \& A. N. Leontiev, Linguagem, desenvolvimento e aprendizagem (13a ed., pp. 59-84). São Paulo, SP: Ícone.

Luria, A. R. (1990). Desenvolvimento cognitivo: Seus fundamentos culturais e sociais. São Paulo, SP: Ícone. (Original publicado em 1976). 
Luria, A. R. (1991). Atividade consciente do homem e suas raízes histórico-sociais. In A. R. Luria, Curso geral de psicologia (pp. 71-84). Rio de Janeiro, RJ: Civilização Brasileira.

Luria, A. R. (2001). Pensamento e linguagem: As últimas conferências de Luria. Porto Alegre RS: Artes Médicas. (Original publicado em 1982).

Luria, A. R. (2015a). A construção da mente (2a ed.). São Paulo, SP: Ícone. (Trabalho original publicado em inglês em 1979).

Luria, A. R. (2015b). Las funciones corticales del hombre (3a ed.). México, DF: Fontamara. (Trabalho original publicado em 1962).

Machado, A. M. (2000). Avaliação psicológica na educação: Mudanças necessárias. In E. R. Tanamachi, M. L. Rocha, \& M. P. R. Proença (Orgs.), Psicologia e educação: Desafios teórico-práticos (pp. 143-167). São Paulo, SP: Casa do Psicólogo.

Marx, K. (1978). Manuscritos econômicos-filosóficos e outros textos escolhidos. São Paulo, SP: Abril Cultural. (Trabalho original publicado em 1932).

Meira, M. E. M. (2012). Para uma crítica da medicalização na educação. Psicologia Escolar e Educacional, 16(1), 136-142. https://doi.org/10.1590/S1413-85572012000100014

Moreno, I. O., Ballesteros, A. C., Burke, F. M., \& Meraz, G. M. (2012). La interacción con los pares y la autorregulación del aprendizaje. In Congreso Internacional de Educación, Chihuahua, México, 1 (pp. 1029-1039). Recuperado de 2016, de http://cie.uach.mx/cd/docs/area_04/a4p9.pdf

Moysés, M. A. A. \& Collares, C. A. L. (2011). O lado escuro da dislexia e do TDAH. In M. G. D. Facci, M. E. M. Meira, \& S. C. Tuleski (Orgs.), A exclusão dos incluídos: Uma crítica da psicologia da educação à patologização e medicalização dos processos educativos. Maringá, PR: EDUEM.

Mújina, V. S. (1985). Caracteristicas psicologicas del prepreescolar y del preescolar. In A. Petrovski (Org.), Psicologia evolutiva e pedagogica (pp. 44-79, L. Salinas, Trad.) Moscou: Progreso Moscú.

Netto, J. P. (2001). Introdução ao estudo do método de Marx. São Paulo, SP: Expressão Popular.

Prestes, Z. (2010). Quando não é quase a mesma coisa: Análise de traduções de Lev Semionovitch Vigotski no Brasil: Repercussões no campo educacional (Tese). Universidade de Brasília, Brasília, DF, Brasil.

Ritalina ${ }^{\circledR}$ (2013). Bula completa. Recuperado de http://www.medicinanet.com.br/bula/4550/ritalina.htm

Salmina, N. G. (2010). Indicadores de la preparación del niño para la escuela. In Y. Solovieva, \& L. Quintanar (Orgs.), Antología del desarrollo psicológico del niño en la edad preescolar. México, DF: Trillas.

Salmina, N. G., \& Filimonova, O. G. (2001). Diagnóstico y corrección de la actividad voluntaria en la edad preescolar y escolar. Tlaxcala, México: Universidad Autónoma de Tlaxcala.

Smirnova, E. O. (2010). El desarrollo de la voluntad y de la voluntariedad en la ontogenia temprana. In Y. Solovieva, \& L. Quintanar (Orgs.), Antología del desarrollo psicológico del niño en edad preencolar (pp. 46-58). México: Trillas.

Solovieva, Y., \& Quintanar, L. (2001). Prologo a la edicion en español. In N. G. Salmina, \& O. G. Filimonova, Diagnóstico y corrección de la actividad voluntaria en la edad preescolar y escolar. Tlaxcala, México: Universidad Autónoma de Tlaxcala.

Solovieva, Y., \& Quintanar, L. (2012). Verificación del éxito escolar. México, DF: Benemérita Universidad Autónoma de Puebla.

Souza, M. P. R. (1997). A queixa escolar e o predomínio de uma visão de mundo. In A. M. Machado, \& M. P. R. Souza (Orgs.), Psicologia escolar: Em busca de novos rumos (pp. 17-33). São Paulo, SP: Casa do Psicólogo.

Souza, M. P. R. (2000). A queixa escolar na formação de psicólogos: desafios e perspectivas. In E. R. Tanamachi, M. L. Rocha, \& Proença, M. P. R. (Orgs.), Psicologia e educação: Desafios teórico-práticos (pp. 105-142). São Paulo: Casa do Psicólogo.

Souza, M. P. R. (2002). Problemas de aprendizagem ou problemas de escolarização? Repensando o cotidiano escolar á luz da perspectiva histórico-crítica em Psicologia. In M. K. Oliveira, T. C. Rego, \& D. T. R. Souza (Orgs.), Psicologia, Educação e as temáticas da vida contemporânea (pp. 177-195). São Paulo, SP: Moderna. 
Stroufe, A. (2012, 28 de janeiro). Ritalin Gone Wrong. The New York Times. Recuperado de http://www.nytimes. com/2012/01/29/opinion/sunday/childrens-add-drugs-dont-work-long-term.html

Tanamachi, E. R., \& Meira, M. E. M. (2003). A atuação do psicologo como expressão do pensamento crítico em Psicologia da Educação. In M. E. M. Meira, \& M. A. M. Antunes (Orgs.), Psicologia escolar: Práticas críticas (pp. 11-62). São Paulo, SP: Casa do Psicólogo.

Tonet, I. (2013). Método científico: Uma abordagem ontológica. São Paulo, SP: Instituto Lukács.

Tuleski, S. C.(2008). Vygotski: A construção de uma psicologia marxista. Maringá, PR: Eduem.

Tuleski, S. C. (2011). A relação entre texto e contexto na obra de Luria: Apontamentos para uma leitura marxista. Maringá, PR: Eduem.

Vieira, A. P. A. (2016). Contribuições da psicologia histórico-cultural para o estudo do desenvolvimento do autocontrole/ autorregulação: Um estudo introdutório (monografia). Universidade Estadual de Maringá, Maringá, PR, Brasil.

Vieira, A. P. A. (2017). O desenvolvimento da atividade voluntária a partir da psicologia histórico-cultural: Menos rótulo e mais aprendizagem (dissertação). Universidade Estadual de Maringá, Maringá, PR, Brasil.

Vygotski, L. S. (1996a). Teoria e método em psicologia (pp. 93-101). São Paulo, SP: Martins Fontes. (Trabalho original publicado em 1960).

Vygotski, L. S. (1996b). Obras escogidas IV. Madrid:Visor.

Vygotsky, L. S. (1998). La modificacion socialista delhombre. In G. Blanck (Org.), La genealidad y otros textos ineditos (pp. 109-125). Buenos Aires: Almagesto. (Trabalho original publicado em 1930).Vigotski, L. S. (2009). A construção do pensamento e da linguagem (2a ed.). São Paulo, SP: Martins Fontes. (Trabalho original publicado em 1934).

Vygotski, L. S. (2012). Obras escogidas III: Problemas del desarrollo de la psique. Madrid: Machado. (Grande parte dos textos foram escritos em 1931 e os primeiros cinco capítulos foram publicado em 1960).

Vygotsky, L. S., \& Luria, A. R. (1996). Estudos sobre a história do comportamento: O macaco, o homem e a criança. Porto Alegre, RS: Artes Médicas. (Trabalho original publicado em 1930).

\section{Ana Paula Alves Vieira}

Doutoranda em Psicologia na Universidade Estadual de Maringá (UEM), Maringá - PR. Brasil. Mestre em Psicologia pelo Programa de Pós-graduação em Psicologia pela UEM, com período sanduíche contemplada pelo programa Becas de Excelencia del Gobierno de México para Extranjeros na Maestría en Diagnóstico y Rehabilitación Neuropsicológica pela Benemérita Universidad Autónoma de Puebla (BUAP), Puebla de Zaragoza - México. Brasil. Especialista em Teoria Histórico-Cultural pelo Departamento de Psicologia da UEM.

E-mail: anapaulaaaa@gmail.com

\section{Záira Fátima de Rezende Gonzalez Leal}

Professora adjunta da Universidade Estadual de Maringá (UEM), Maringá - PR. Brasil. Doutora em Psicologia Escolar e do Desenvolvimento Humano pela Universidade de São Paulo (USP), São Paulo - SP. Brasil. Mestre em Educação pela Universidade Estadual Paulista Júlio de Mesquita Filho (Unesp), Assis - SP. Brasil.

E-mail: zairagleal@gmail.com

Endereço para envio de correspondência

Programa de Pós-Graduação em Psicologia (PPI) da Universidade Estadual de Maringá (UEM).

Av. Colombo, 5790 - Zona 7, Maringá - PR, 87020-900, Brasil

Recebido 08/06/2017

Reformulado $30 / 11 / 2017$

Aprovado 23/01/2018 
Received 06/08/2017

Reformulated $11 / 30 / 2017$

Approved $01 / 23 / 2018$

Recibido 08/06/2017

Reformulado 30/11/2017

Aceptado 23/01/2018

Como citar:Vieira, A.P.A.V.; Leal, Z.F.R.G.L. (2018). Enfrentando as Queixas: o Desenvolvimento da Atividade Voluntária para a Psicologia Histórico-Cultural. Psicologia: Ciência e Profissão, 38(4), 680-695. https://doi.org/10.1590/1982-3703002052017

How to cite:Vieira, A.P.A.V.; Leal, Z.F.R.G.L. (2018). Facing the Complaints: the Development of Voluntary Activity for Historical-Cultural Psychology. Psicologia: Ciência e Profissão, 38(4), 680-695.

https://doi.org/10.1590/1982-3703002052017

Cómo citar:Vieira, A.P.A.V.; Leal, Z.F.R.G.L. (2018). Enfrentando las Quejas: el Desarrollo de la Actividad Voluntaria para la Psicología Histórico-Cultural. Psicologia: Ciência e Profissão, 38(4), 680-695. https://doi.org/10.1590/1982-3703002052017 